These articles will not retain the perspiration and become cold and clammy, but allow free evaporation, and are sold under the titles of "Health" Chest Protectors and "Transpirable" Belts and Vests.

RoBertson and Co. (Operative Chemists, 35, George Street, Edinburgh) showed an excellent series of preparations; among them their valuable Acidified Perchloride of Mercury Pellets for immediate formation of an Antiseptic Solution, as originally introduced; Berozine Cream, Antiseptic Dusting Powder original preparations for the skin. Borozine is designed to combine the emollient properties of oxide of zinc, with the antiseptic and detergent effects of boric acid being a chemical combination of these substances; it is especially recommended in cases of skin irritation. Flexible Gelatine Capsules ; Blaud's Ferruginous Pill Mass in Capsules, by patent process for forming nascent carbonate of iron after administration. These are capsules containing the genuine Blaud's Pill Mass, and they form an admirable preparation of iron, which has a well-established reputation. Sulphonal in Capsules by special patented process, getting over a frequent difficulty in administering this valuable hypnotic, and an extensive variety of other drug combinations in capsules. Granulated Effervescent Preparations of excellent character, and a number of Glyco-Gelatine Pastilles for the exhibition of various potent drugs in a palatable form. Their Vaseline Combinations for use as an antiseptic dressing in midwifery and in surgery contain the various medicaments in a soluble and homogeneous form; they are put up in collapsible tubes of 1,2 , and $4 \mathrm{oz}$. each, a most convenient form of carriage for the busy practitioner.

Messrs. Allen and Hanburys exhibited, in addition to the usual features, some noteworthy New Foods for Infants. We believe that this is the first time that it has been attempted to introduce a series of foods with the view of meeting the requirements of an infant during the successive various stages of development of its assimilative powers. It is desired to gain experience of their keeping properties, which is very important from a commercial point of view. Several leading physicians. however, have made important experiments with them, and are greatly pleased with the result, and before long they are likely to be brought prominently to the notice of the profession. These preparations are of more than ordinary interest. No. 1 Food, designated " First Food for Infants," is believed to be specially adapted to infants from birth to 3 months of age. It is prepared from fresh and carefully selected cow's milk (the proximate composition of which has been first ascertained), by removing the excess of casein, and adding sufficient cream (fat), albumen, and milk-sugar to bring up the quantities of these constituents to the required standard. The resulting food is then sterilised, concentrated in vacuo, and preserved in hermetically closed vessels. No. 2 Food, desig nated "Mother's Milk Fond," is specially adapted to infants under 7 months of age. It is designed for infants of 3 months of age and upwards. At this age it is thought desirable to supply, in addition to the required nutriments in due proportions, some slight stimulus to the exercise of the digestive functions. This food consists of the No. 1 Food, with the addition of some maltose and a small proportion of dextrine with some soluble phosphates resulting from the mashing of crushed whole wheat with barley malt. The presence of a certain proportion of dextrine supplies the desired stimulus to the digestive functions, and the whole having been filtered in the liquid condition, no unconverted starch exists in the food. It is therefore entirely free from any tendency to produce the injurious effects sometimes resulting from the use of farinaceous foods, even if it is given at a very early age. The food is finished by concentration in vacuo, and packed in close vessels. It is very palatable, and, like the "First Food," is a complete food, containing the milk required and only needing the addition of hot water. This is a point to be borne in mind in reference to cost. A yet more important point is that the milk is sterilised, and therefore cannot convey the germs of disease often present in cow's milk. It is also uniform, an advantage difficult to secure when fresh cow' milk is used. No. 3 Food, designated "Malted Food," is specially adapted to infants of 6 months of age and upwards. It is the food which Messrs. Allen and Hanburys have made for many years. The large experience gained during this period has abundantly indicated the value and practical effcacy of this food. The basis of this food is fine wheaten flour specially selected for its richness in nitrogenous constibuents. This is carefully subjected to heat, and then to the aetion of a proportion of malt extract, sufficient to ensure the eonversion of a large proportion of the starch; it is then carefully dried at a gentle heat. Another special object in the exhibition of this firm were some new forms of ozonisers for the production of ozone in the sick room or wards of a hospital. Hitherto apparatus for produciug ozone has either been expensive or not adapted to generate the gas in large quantity. These difficulties have been overcome, and now, by means of an apparatus recently designed and patented by Mr. Emile Andreoli, this valuable disinfectant and stimulant is rendered available for use in private houses and hospitals at a very moderate cost. The older forms of apparatus were generally tubular, air or rather oxygen being sent through a passage of minute dimensions between two concentric glass tubes; such tubes, fitted with electrodes, were necessarily costly, and required to be employed in considerable numbers, in order to produce any sufficient supply of ozone. Further, some apparatus was always needed in order to drive the oxygen or air through the ozonizer, even when only quite small quantities were desired, as for diffusion in an ordinary room. The invention of $\mathbf{M r}$. Andreoli is based on the well-known tendency of electricity to flow off from a point, and the characteristic feature of his apparatus is that the electrodes (one or both) bear numerous points. The advantage thus gained is that the apparatus will work in the air of any apartment, the ozone, as formed, diffusing through the room without any tube or other enclosure, or any mechanical means for producing a draught. For otherpurposes, the apparatus, which is relatively inexpensive, can be placed in a case through which oxygen or air is driven, whether by machinery or by an apparatus similar to that used for producing sprays; and the ozoniser can be repeated any number of times, or be of any form or dimension to suit theenclosing case, according to the quantity of ozone to be produced. The supply of Mr. Andreoli's apparatus has been undertaken by Allen and Hanburys, of Plough Court, Lombard Street, E.C., and of 7, Vere Street, Cavendish Sqaure, W.

Mraby's Tritrcumina Co. (7, St. Paul's Churchyard, E.C.) showed Malted Wheat Food for Infants, Children, and Invalids, and Entire Wheatmeal Digestive Bread, the starch of which has been largely converted to dextrine by the special mode of malting the wheat prior to grinding into meal.

The Bovinine Co. (32, Snow Hill, E.C.) showed their Bovinine, which is now thoroughly well known in the profession as an excellent preparation of the juice of lean uncooked beef in which the nutritious albuminoid elements are preserved, in addition to the meat salts and extracted matter. It contains 20 per cent. of coagulable albumen, and has deservedly found general favour in respect to its excellence, efficiency. and economy. It has from the first $(1878)$ been introduced strictly to the profession, and is being largely used in cases of mal-nutrition or mal-assimilation, convalescence, in diarrhœic and dysenteric conditions, and for other cognate purposes.

\section{THE GRESHAM UNIVERSITY.}

THE Royal Commissioners, to whom the question of an efficient teaching university for London has been referred, have already held twenty-three sittings, and the Commission. now stands adjourned until October 13 th.

The terms of the Commission, it will be remembered, are made so wide that they will cover all projects which may be thought worthy of consideration for including the existing. London University in any scheme.

The new Commission does not contain the names of any of the members of the old Commission, but Mr. James Anstie, Q.C., B:A., who gave evidence before the Commission in 1888, is a member of the new Commission.

The witnesses who have been examined, and who also gave evidence before the old Commission, include the following gentlemen: Mr. William Henry Allchin, M.B., F.R.C.P. M.R.C.S., Physician and Lecturer to Westminster Hospital and Examiner to the Royal College of Physicians; Sir Andrew 
Clark, Bart., LL.D., M.D., President of the Royal College of Physicians, Phrsician and Lecturer on Clinical Medicine at the London Hospital, and ex.President of the Clinical Society; Mr. William Job Collins, M D., M.S., B.Sc., F.R.C.S. ; Mr. John Eric Erichsen, LL.D., F.R.S., member of the Council of the Royal College of Surgeons and of the Council of University College, and Consulting Surgeon to the Hospital ; Sir Joseph Lister, Bart., D.C.L., F.R.S., member of the Council of the Royal College of Surgeons, Surgeon to King's College Hospital, and Fellow of University College ; Mr. Norman Moore, M.A., M.D., F.R.C.P., Warden of the College, Assistant Physician and Lecturer on Comparative Anatomy at St. Bartholomew's Hospital ; Sir James Paget, Bart., F.R.S. ; Mr. William Overend Priestley, M.D., LL.D.; and Mr. Frederick Taylor, M.D.Lond., F.R.C.P., Senior Assistant Physician and Lecturer at Guy's Hospital.

Other witnesses include Mr. Stanley Boyd. M. B, B S. F.R.C.S.; Thomas W. Shore, M.D. B.Sc.; W. Howship Dickinson, M.D., F.R.C.S.; Herbert William Page. M.A., M.B., M.C., F.R.C.S., Surgeon and Lecturer at St. Mary's Hospital; J. Frank Payne, M.D., B.A., F.R.C.P., Physician and Lecturer at St. Thomas's Hospital: G. Spence, M.B., M.S., F.R.C.S.; E. A. Schäfer. F.R.S. Jodrell Professor of Physiology at University College and Lecturer on Chemistry to the London School of Medicine for Women; J. Whitaker Hulke, F.R.S. member of the Council of the Royal College of Surgeons, and of Middlesex Hospital, President of the Pathological Society, and Fellow of King's College; H. G. Howse, M.S., M.B., F.R.C.S., Surgeon and Lecturer on Anatomy to Guy's Hospital; C. Macnamara, Surgeon and Lecturer to Westminster Hospital and Fellow of King's College; Mr. Liveing, and Mr. Boor Crosbie, who was called on behalf of the Gresham Committee.

Mr. James Anstie, Q.C., B.A., who is a member of the Commission, gave evidence before the Commission of 1888, and upon that occasion he said that he considered a teaching university would injure the University of London more than any other teaching university in the kingdom, as it would withdraw from the University of London the whole of the teaching apparatus and teaching power and resources of the metropolis. The question of obtaining the University of London degree in addition to other degrees principally applied to the medical degree but if a new medical university were established in Londonand he did not see how it could be possibly avoided if any teaching university were established in London-it would have itself possession of all those resources and means and appliances necessary to medical education; and, on the ordinary principles of human nature, it would undoubtedly give a degree of the very highest kind, and one that could not be outstripped by any university, so that there would no longer be any motive for taking the University of London degree. And such a university would, no doubt, give ordinary degrees, too. A teaching university in which examinations were conducted by the teachers, with additional examiners, would, for the reasons he had stated, necessarily annihilate the University of London, and would reduce it to an institution for provincial or extra-metropolitan students of a certain amount of value; but a university which was entirely cut off from association with the influences of teaching and teachers would not, he considered, be a university of a very high degree of value, and he would, therefore far rather see the University of London abolished at once. than left with this meagre remnant of a supposed function which it never could adequately discharge With the greatest submission, he could not accept the position that the examination for the degree of the University of London must be greater than that in teaching universities. With regard to the ordinary degrees, they were probably, rather higher; but with respect to the highest degrees, excepting the Faculty of Medicine, he did not know that anyone had ever claimed for the London degrees that they were superior to those of Oxford and Cambridge. With respect to medical degrees, it was perfectly true that they were of a higher standard. Everybody had told him so, therefore he was bound to believe it; and it was true also with respect to the Master of Arts degree. A good deal of evidence was given before the old Commission, and to a great extent the same opinion still prevails, that the examinations for medical de- grees in the University of London were of too high a standard in reply to which Sir James Paget, Vice-Chancellor of the University, prepared the following statement:

In many portions of the evidence given before the Royal Commission there are indications of error or misunderstanding in regard to the examinations for medical degrees of the University of London. Especially, the examinations are spoken of as being too severe and too scientific to be passed by many students on whom a M.D. degree might justly be conferred.

1. Beginning with the Matriculation Examination, it is said that it requires more knowledge than can fairly be expected in a student of 17 or 18 unless he has been educated in one of the best schools, or be of unusual ability; that the subjects are too numerous; and that the requisite knowledge is commonly attained by "cramming."

In answer to these statements it may be said-

1a. There are no indications of students being deterred. The number of candidates for matriculation has constantly increased. It has been doubled every twelve years without any increase in the proportion rejected ; and in the last half-yearly examination there were 1,779 candidates, of whom 1,041 passed.

$1 b$. In the last year's registration by the Medical Council of students qualified to begin the study of medicine by having passed a preliminary examination either in a University or in the Cambridge or Oxford local centres, or in the one of many other places sanctioned by the Council, only one of the examinations had been passed by more than that for the matriculation of the University. This one was the examination held by the College of Preceptors under the sanction of the Medical Counci!, and the most convenient for the majority of English students intending to proceed in medicine. It was passed by 325 of the students, and 281 passed the matriculatic $n$

1c. The subjects are not more numerous than in the majority of the corresponding examinations recognised by the Medical Council. They are the same as in the College of Precentors.

$1 d$. It is not possible to estimate exactly the degrees of severity in different examinations on the same subjects; but the proportion of candidates rejected at the matriculation is not more than the evidence at the other examinations, and is considerably less than at the examination by the College of Preceptors, though this is generally regarded as setting a lower standard, and the classes are generally drawn from similar classes of students.

le. As to "cramming," there is no evidence that it is more resorted to for the matriculation than for any other examination of the kind.

2. The examinations after matriculation, which must be passed for the M.B. and the M.D. degrees are also said to be too many, too difficult, and too scientific, rather than practical. To this it may be answered :

$2 a$. The subjects of siudy are exactly the same as for nearly all other medical degrees and diplomas, with the exception of an examination in elementary biology at the very beginning of study.

$2 b$. The number and order of the examinations are also the same, except in that two years instead of one must elapse between the first and second.

$2 c$. The time required for passing them all is the same as for other degrees or diplomas qualifying for practice. All those required for the M.B. may be passed in four years, and although many students take five years, this is no more than many do who pass the conjoint examination of the Colleges of Physicians and Surgeons, and is not more than, I believe, would be made compulsory on all students if it were not for the additional expense of a fifth year's study.

$2 d$. As for the examination being what is called too scien: tific and not practical, there is not in the University any examination whatever in any of the special scientific subjects after the examination at the end of the second year's study is passed, and the examinations in medicine, surgery, and midwifery are wholly practical. They are, for the M.B., in range and methods similar to those of the Colleges of Physicians and Surgeons. The examiners are always selected from among physicians of high repute who are in practice, and are or recently have been, teachers; they are chosen from all 
schools indifferently, and the examination differs in nothing from others of which the passing confers the right to practise except in being more complete and more difficult than some are. I think it certain, both from my own observation and from the opinions of others, that the examinations for the M.B. degree of the University could be passed by any of those who pass creditably the conjoint examination of the two Royal Colleges. Especially in the final examinations there is nothing more scientific, nothing less practical, in the one than in the other.

3. I would say the same of the examination for the M.D. degree. It is in the same sense practical, whether it is written, or oral, or clinical part as is the Final Examination for the M.B.; there is nothing in it more theoretical, or what is called scientific, than there is in the busy part of a physician's daily practice. Only it requires, as does the M.D. in most other universities, two years' longer study and more and higher knowledge than does the examination for the M.B.

In maintaining this standard much higher than that requigite for the mere right to practice the University is not alone even in London, as the College of Surgeons admits Member to its Fellowship after longer study and a severe examination; the College of Physicians by careful selection.

I mentioned in my evidence some facts in proof of the high positions occupied by doctors of medicine of the London University. One was that from among them have been selected nearly half of the physicians and of the assistant and obstetric physicians to the principal hospitals in London. This may, at least, show that the studies and examinations necessary for the degree did not tend to make them unpractical. The same may be said of a large number of the leading provincial physicians and of the many surgeons of repute who hold the M.B. of the University.

And a yet stronger evidence of the eminence in practice of the physicians who hold the University degree is in the list of Fellows of the Royal College of Physicians. They are carefully selected from members of most repute wherever they may be in practice. The number elected in the last twenty years, among whom are graduates of twenty universities, is 205 , and of these 61 have degrees of the University of London. Again, it is observed that comparatively few of those who take the M.B. in London proceed to the M.D., and this is regarded as a fault of the examination. The proportion of those who do take the higher degree is greater in London than in Cambridge, and in both cases the diminution may be explained without discredit to the examinations. Some of the graduates after taking the M.B. become surgeons and would rather not be deemed physicians; some go at once into practice, and have no opportunity or inclination for continuing the studious clinical work requisite for the higher degree, and some are content with the M.B., which by courtesy is regarded as giving the title of doctor.

$$
\text { (Signed) James Paget. }
$$

\section{CHARING CROSS HOSPITAL.}

\section{Post-Graduatr Class and Lactures.}

Special series of clinical lectures and practical demonstrations, exclusively arranged for the convenience of practitioners and post-graduate students, are given, at the hospital by members of the staff throughout the year. The lectures for the year are arranged in three courses, each course consisting of ten meetings, and lasting ten weeks. Two of these courses are held during the winter, and one during the summer. The class meets on each Thursday afternoon, at 4 P.M., in the board room of the hospital, and proceeds thence to the wards or other department in which the demonstration may be held. The fee at present charged for each course of ten lectures is one guinea. The first of the two winter courses of the ensuing academical year will commence on October 13th next, and will be conducted by the following members of the medical and surgical staff: Drs. Green, Bruce, Willcocks, Murray, Mott, Routh, Arkle, and Messrs. Bloxam, Boyd, and Waterhouse.

Practitioners wishing to join the class can receive any further information as to the dates and subjects by communicating with the Honorary Secretary (Dr. Willcocks) or the Honorary Treasurer (Mr. Boyd) at the hospital.

\section{HOSPITALS AND MEDICAL SCHOOLS.}

THE following were received too late for insertion in their proper place in the Students' Number of the BRITISH MEDICAL JouRnaL published on September 3rd:

City of London Hospital for Diseases of the Chest, VICTORIA PARK.-Consulting Physicians: Drs. J. Andrew and E. L. Birkett. Consultrng Surgeon: J. Eric Erichsen, F.R.S. Physicians: Drs. J. C. Thorowgood, Eustace Smith, G. A. Heron, Vincent D. Harris, J. A. Ormerod, and E. Clifford Beale. Surgeon: j. F. C. H. Macready, F.R.C.S. Assistant Physicians : Drs. Harrington, Sainsbury, T. Glover Lyon, Sir Hugh R. Beevor, Bart.; W. J. Hadley, and E. H. Colbeck.

During the past year 1,236 in-patients have been admitted, and the large number of 25,500 cases have been treated since the opening of the wards in 1855 . The number of out-patients treated during 1891 was 15,529 , and 489,890 since the commencement of the institution in 1848 .

Works are in progress in connection with the drainage and sanitary arrangements. The scheme provides for two detached towers to contain all the sanitary appliances. One of these towers has been completed and is in use.

Information as to medical instruction can be obtained on application to the Secretary of the Clinical Subcommittee at the hospital.

Liverpool Royal Sodthern Hospital : Clinical School. -Physicians : Dr. Cameron, Dr. Carter, and Dr. Williams. Surgeons : Mr. Rawdon, Mr. Alexander, and Mr. Robert Jones. Medical Tutor: Dr. Macalister. Surgical Tutor: Mr. Davey. Pathologist: Dr. Barendt. The hospital is situated within convenient distance of the School of Medicine, and contains 164 beds. There is a children's ward, and beds are appropriated to the diseases of women. Clinical teaching is given in the hospital, and arrangements have been made to render it both thorough and systematic. The members of the staff visit the wards daily, and clinical lectures are given each week. Tutorial classes are also held each day, at which the junior students are instructed in the methods of diagnosis, and the seniors are prepared for their final examinations. The pathological department has a good laboratory attached in which the students receive practical instruction. In addition to the usual clinical and post-mortem clerkships, the resident post of ambulance officer is awarded every three months to the student whom the board may consider most suited to hold it. A scholarship of $£ 20$ is competed for annually, which has attached to it some clinical and pathological duties, and three prizes of $£ 5$ each are yearly offered for the best series of clinical reports.

Fees.-Perpetual, £26 5s. ; one year, $£ 10$ 10s.; six months, $£ 77 \mathrm{~s}$; three months, $£ 44 \mathrm{~s}$. A limited number of resident pupils can be received; terms (exclusive of fees for hospital practice), $£ 1515 \mathrm{~s}$. per quarter. The practice of the hospital is recognised by all examining bodies. Further particulars may be obtained from the Dean, Mr. Robert Jones, 11, Nelson Street, Liverpool.

St. Vincent's Hospital, Deblin.-Consultant : Dr. Quinlan. Physician and Lecturer on Medicine: Dr. Cox. Physician and Lecturer: Dr. McHugh. Physician to Extern Department and Assistant Lecturer : Dr. Savage. Surgeon and Lecturer on Surgery: Mr. McArdle. Surgeon and Lecturer: Mr. Tobin. Surgeon to Extern Department and Assistant Lecturer : Dr. Patteson. Gynacologist and Lecturer on Gynacology: Dr. Smith. Patiolngist and Lecturer on Pathology: Dr. Patteson. Dentist and Lecturer on Dentistry. Mr. Bloom. Pharmaceutist and Lecturer on Pharmacy: Mr. Flood. Resident Surgeon: Mr. Lynch. Resident Physician: Dr. Marnell.

This hospital contains 160 beds, constantly occupied by the most instructive cases, and has attached to it a crowded dispensary and three special dispensaries. During the nine month ending June 30th, 1891, 581 medical and 455. surgical cases, together with 110 cases of diseases of the eye and ear, were treated within the wards. The attendance at the dispensaries during the same period has considerably exceeded 14,000 cases. The whole practice of the hospital is available for clinical instruction, which is carried on during the session in a systematic manner from 9 to 12 o'clock in the fore- 